\section{Laparoscopic Partial \\ Hepatectomy for Inflammatory Pseudotumor of the Liver}

A 50-year-old man was admitted for further examination of a $10-\mathrm{mm}$ hepatic mass in subsegment 4 . He had cirrhosis of the liver as a result of alcohol abuse, and hepatitis virus markers were all negative. Dynamic computed tomography (CT) revealed a $10-\mathrm{mm}$ hypervascular tumor in the early phase (Figure 1). On angiography, the tumor was hypervascular, and arterial portographic CT showed that the tumor was low density, indicating that it had no portal flow. Based on these findings, preoperatively we considered the tumor to be a hepatocellular carcinoma.

As the tumor was small and located at the edge of the liver, we resected it by laparoscopic partial hepatectomy [1,2]. Under general anesthesia, pneumoperitoneum was induced with $\mathrm{CO}_{2}$ gas using a $\mathrm{CO}_{2}$ insufflator. The tumor could be observed laparoscopically at the edge of the liver (Figure 2). The surface of the liver was nodular, and appeared to exhibit complete cirrhosis. After the extent of the tumor was carefully determined with laparoscopic ultrasonography, the tissues surrounding the tumor were punctured with an electrode needle and coagulated with $80 \mathrm{~W}$ for 45 seconds with a microwave tissue coagulator (Microtaze OT-110M; Nippon Shoji Ltd., Osaka, Japan) [3]. The coagulated tissues were dissected with an ultrasonically activated scalpel (Laparosonic Coagulating Shears (LCS); Johnson and Johnson Medical, K.K., Tokyo, Japan) [4]. The resected liver tissue was placed inside a plastic bag. The bag was then extracted through a slightly enlarged wound created by puncture of the trocar. Bleeding was minimal, and no problems were noted during the operation. The patient recovered soon after the operation.

The resected tumor was well circumscribed, but not encapsulated, and the surrounding tissue appeared cirrhotic. The resected specimen was diagnosed histologically as an inflammatory pseudotumor. This is the first report of inflammatory pseudotumor of the liver observed laparoscopically and resected by laparoscopic hepatectomy.

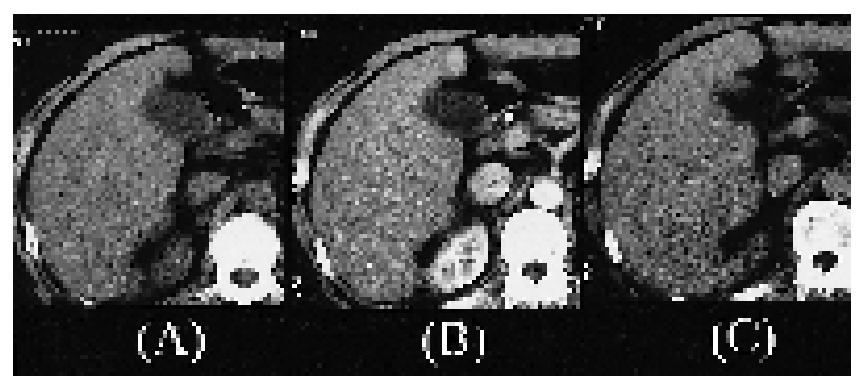

Figure 1 A Plain computed tomography $(\mathrm{CT})$ revealed a low-density tumor in subsegment 4. B The tumor became high density in the early phase on dynamic CT. C The tumor was still high density in the delayed phase

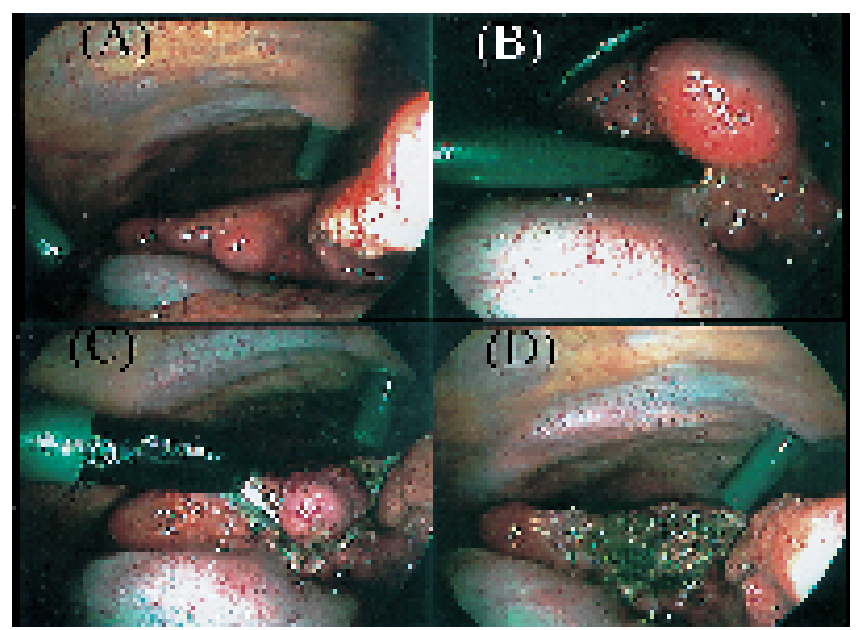

Figure 2 Laparoscopic observation. A The tumor was at the edge of the liver. B The tissue surrounding the tumor was punctured with an electrode needle and coagulated.

C The coagulated tissues surrounding the tumor were dissected with an ultrasonically activated scalpel. D The cut edge of the liver was observed

S. Seki ${ }^{1}$, H. Sakaguchi ${ }^{2}$, R. Oiso ${ }^{1}$, C. Lee ${ }^{1}$, H. Morikawa ${ }^{1}, H_{\text {. Hamba }}{ }^{2}$, S. Kubo ${ }^{1}$, K. Hirohashi ${ }^{2}$, H. Kinoshita ${ }^{2}$

${ }^{1}$ Third Dept. of Internal Medicine,

Osaka City University Medical School, Osaka, Japan

${ }^{2}$ Second Dept. of Surgery, Osaka City

University Medical School, Osaka, Japan

\section{References}

${ }^{1}$ Cuesta MA, Meijer S, Paul MA, et al. Limited laparoscopic liver resection of benign tumors guided by laparoscopic ultrasonography: report of two cases. Surg Laparosc Endosc 1995; 5: 396-401

${ }^{2}$ Kaneko H, Takagi S, Shiba T. Laparoscopic partial hepatectomy and left lateral segmentectomy: technique and results of a clinical series. Surgery 1996; 120 : $468-475$
${ }^{3}$ Tabuse K. A new operative procedure for hepatic surgery using a microwave tissue coagulator. Arch Jpn Chir 1979; 48: $160-172$

${ }^{4}$ Kadesky KM, Schopf B, Magee JF, et al. Proximity injury by the ultrasonically activated scalpel during dissection. J Pediatr Surg 1997; 32: 878-879

\section{Corresponding Author}

H. Sakaguchi, M.D.

Third Dept. of Internal Medicine Osaka City University Medical School 1-4-3 Asahimachi

Abeno-ku

Osaka 545-8585

Japan

Fax: $\quad+81-6-66453813$

E-mail: m6332543@msic.med. osaka-cu.ac.jp 